\title{
Grade Validity Of Online Quantitative Courses
}

\author{
Judson C. Faurer, Metropolitan State University of Denver, USA
}

\begin{abstract}
Are prospective employers getting "quality" educated, degreed applicants and are academic institutions that offer online degree programs ensuring the quality control of the courses/programs offered? The issue specifically addressed in this paper is not with all institutions offering degrees through online programs or even with all online courses. The concern is with those online courses where the means to ensure the validity of course grades is not guaranteed by measures of technology or academic rigor employed. More specifically, the practical measures to reduce or eliminate doubts about a student's acquired knowledge in quantitative online courses need evaluation and thought to arrive at a more circumspect solution. Is the grade earned truly indicative of a student's competency and level of acquired knowledge and understanding in an online quantitative course or merely an indication that the student somehow just satisfied proscribed evaluative criteria set by the faculty member without adequate measures of assessment?
\end{abstract}

Keywords: Grade Validity; Online Quantitative Courses

\section{INTRODUCTION}

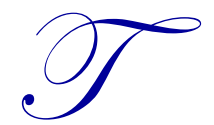

he CBS evening news on 31 December, 2007 devoted its closing comments to the booming online college education in this country and, with the increased enrollment, the proliferation of fraudulent degrees offered by online degree mills. The concern expressed was the alarming increase in the number of business and government agencies that no longer accept academic degrees from job applicants who received their degrees from such sources. This brings into question the validity of degrees received even from acknowledged accredited online degree programs. Are prospective employers getting "quality" educated, degreed applicants and are academic institutions that offer online degree programs ensuring the quality control of the courses/programs offered?

The issue specifically addressed in this paper is not with all institutions offering degrees through online programs or even with all online courses. The concern is with those online courses where the means to ensure the validity of course grades is not guaranteed by measures of technology or academic rigor employed. More specifically, the practical measures to reduce or eliminate doubts about a student's acquired knowledge in quantitative online courses need evaluation and thought to arrive at a more circumspect solution. Is the grade earned truly indicative of a student's competency and level of acquired knowledge and understanding in an online quantitative course or merely an indication that the student somehow just satisfied proscribed evaluative criteria set by the faculty member without adequate measures of assessment?

Much research has been accomplished related to cheating in both online and traditional classroom courses. Obviously cheating to improve or influence a grade in a course is not condoned. Suggestions on how to reduce or eliminate unethical conduct on the part of students all have their appeal and seemingly sound rationale but, nevertheless, the literature would lead us to believe and accept that such action by students is, to a larger extent than desired, inevitable. Either planed or panic cheating is acknowledged by $95 \%$ of students surveyed (Rowe, 2004). But it is not the cheating alone that should capture attention but the ramifications for students, potential employers of degreed graduates, and the academic institutions awarding grades that do not reflect true assessment of knowledge gained. For the cheaters there are the consequences of grades received that delude the student into believing he/she 
possesses the knowledge to solve problems, generate ideas, behave in meetings or perform in general on the job (Batero, no date). With more employers relying on possession or attainment of a degree as one criteria for hiring or promotion and a measure of an applicant's/employee's knowledge, there needs to be assurance that an academic degree is a valid indication of acquired learning. It should not be incumbent on organizations to have to test an applicant's knowledge of or competency with mathematical concepts, for instance, when transcript grades or basic degree content should attest to qualifications. The degree granting institution also shares in the consequential disillusionment or grades, programs, or degrees related to the institutions where the reputations are tarnished by faulty grading of coursework.

\section{WHAT CONTRIBUTES TO FAULTY GRADE ASSESSMENT?}

There is an implicit trust in a grade assigned by any evaluative measure be it for investments opportunities, food products, or academic performance in a course. The A, B, C, etc. designator should be taken in good faith as a true measure of quality arrived at through stringent application of widely accepted evaluative processes (Rowe, 2004). In academe assessment is central to education because the primary purpose of an educational institution is to validate student knowledge. If an institution claims to provide a service, it must prove to society that it does so by some valid assessment mechanism. To do otherwise is to sacrifice an institution's reputation so important to accreditation and survival.

The online degree mills incur suspicion of their programs for several reasons. Those with purely adjunct faculty or, in some cases, no faculty at all, cannot help but draw attention to their grading practices. Additionally, the existence of faculty possessing an academic degree does not necessarily guarantee good instructors capable of imparting and discerning quality learning. One of the largest online degree granting institutions in the U.S. employs only adjunct faculty who are not primarily educators by trade. While its institutional research monitors "means" and variances of grades awarded, conducts online peer reviews, and tracks classroom activities, the use of student "learning team" groupings can foster collusion in the submission of individual graded assignments and online examinations. While there could always be an element of faculty bias or disposition in final grade determination, the focus in this discussion is on the work received from the student for grade determination.

The point to be made is that no doubt the majority of online students probably is interested in and dedicated to learning but external factors, consciously or unconsciously, may contribute to the seeking of unapproved resources when completing assignments or examinations. Time constraints, quest for survival, limited knowledge, personal values, and societal factors may confound the "already fuzzy realm of academic honesty" (Varvel, 2005). Furthermore, matters are exacerbated by the ignorance or even indifference of instructors or administrators of the possibilities for cheating in online assessment. Full-time, tenured faculty could view assessment processes differently than adjunct faculty who may not share a vested interest in academe while earning a few dollars in a part time job.

\section{PRO AND CONS OF METHODS TO IMPROVE GRADE VALIDITY}

Again, considerable research has been undertaken to suggest methods, tools, and practices to reduce or eliminate cheating with its concomitant impact on grade validity. Most seem to be directed toward examination administration. Depending on how course assessment is structured by each faculty member, examination scores as a percent of course grade may vary significantly. It is imperative, therefore, that any attempt to control grade validity encompasses measures addressing all graded individual assignments. Is this an unrealistic task? Perhaps, but, without grade integrity all education may be compromised.

Securexam: this product controls a computer's operating system during a test, locking out files so students can't seek answers in directories or on the internet (Healy, 2001). Its drawbacks are tech-savvy students finding ways around any blocking device, cost and need for leasing agreement, and professors' degree of comfort with teaching technology (Healy, 2001). It would of little help with graded homework assignments.

Oncourse: this is another proprietary system used to detect examination cheating online not unlike other products in Blackboard or WebCT but they do not eliminate external assistance being present during accomplishment of examinations or other graded assignments (5). 
Interactive student centered paradigms: by developing a sense of community among students with everyone contributing to the learning process, it is proffered that "a sharing, communal atmosphere may help to reduce both the desire and need to cheat" (Varvel, 2005). This idealistic viewpoint borders on naivety. Personal experience with Learning Teams would suggest that while cheating may be reduced (viewing of other Learning Team members' online inputs or collaborating), the assumption that all team members contribute equally and thus deserve similar grades or demonstrate equal grade competence if foolhardy. A good percentage of team members will ride along on others efforts.

Use of testing protocol: used by some professors at Indiana University Southeast, it too is an idealistic appeal to individual ethical integrity. It spells out expectations regarding examinations administered online outside of normal class time. While it may sound great, based on the statistics of student cheating its compliance is in the realm of believing in the tooth fairy.

\section{ATTENTION TO EXAMINATION CONSTRUCTION}

Open book examinations: any online examination must invariably accept an open book environment unless proctored along with included blocking devices.

Same examination, different numbers: there is some merit to this type examination construction but it is time consuming, almost prohibitive in large classes, and does not preclude others being present with the examination taker (Connecticut Distance Learning Consortium, no date).

Random selection from question pool: to effectively use this method of online testing, a sufficiently large test bank would be required. As with most test banks, there is no assurance that all questions will have the same degree of difficulty or character (factual vs. applied). Certainly application based questions are preferable because they require that students not only know the material but that they also know it well enough to apply it to practical situations (Epilon, 2007). Building a sufficiently large application type question pool is an insurmountable task for the traditional instructor. A serious problem with pools is that instructors systematically underestimate how large the pool must be to make negligible the overlap of questions between tests (Rowe, 2004). Most instructors do not have the patience or resources to provide an adequately large pool (Rowe, 2004). An alternative to random selection from a large question pool is scrambling the same limited number of questions. Combined with a time limit on examination time, this approach does add the dimension of inhibiting collaboration especially if an examination consists of many scrambled questions.

Other: limited test time, number of available test days, number of attempts, and special password are all added hindrances to the seeking of assistance during a test period but are still no assurance of the "taker's" ID or lack of assistance.

Restriction on downloading: in spite of general technological checks built into the online programs, computer savvy students find ways to bypass them. Even with examinations that limit the number of attempts and duration of an examination, the downloading of an examination and emailing it to classmates is not uncommon. Although this practice may not benefit students in a current class, it does not preclude students from compromising examinations used by faculty in subsequent semesters. Writing new examinations, especially multiple choice or True/False, each semester is a daunting task. Using an existing test bank, for reasons mentioned earlier, may have also been compromised by downloading.

\section{SOLUTIONS}

If educators are truly concerned about grades awarded in online quantitative courses being a valid indicator of learned course content and share the concern of employers who expect grades to be a benchmark of competency in subject matter, then there must be integrity in the assessment methods used to determine grades. The only viable solution is proctored examinations. Unfortunately such a solution to assuring grade validity for online quantitative courses runs counter the basic premise for online courses - being able to complete a course without physical presence in a ground classroom, at one's convenience, anywhere in the world where access to a computer is 
available. However, the suggested solution merely means a student must find an approved proctor who would meet the requirements set up by the instructor for items such as length of time for examination, access to outside materials, etc.

\section{AUTHOR INFORMATION}

Judson C. Faurer, has been teaching Organizational Management at Metropolitan State University of Denver both in the classroom and online since retiring from the Air Force in 1983. In this role he has had an opportunity to do research for companies such as Arby's, Conoco, and U.S. West. He entered the U.S. Military Academy at West Point following a year at Penn State. His career in the Air Force was primarily in Missile Operations and along the way had duty assignments at the U.S. Air Force Academy, as an advisor in Vietnam, and in Washington D.C. along with a few other places. He has an MBA from Ohio State and a Ph.D. in Higher Education from the University of Denver. E-mail: JFaurer@MSUDenver.edu

\section{REFERENCES}

1. Botero, O. (no date). "Consequences of Cheating”, TOPICS Online Magazine, Issue 13.

2. Connecticut Distance Learning Consortium. (no date). "Avoiding Cheating in Online Classes: Suggestions for Assessing Student Learning".

3. Eplion, D. and Keefe, T. (2007). "Practical Tips for Preventing Cheating on Online examinations", Faculty Focus newsletter.

4. Grijalva, T., Kervleit, J., and Nowell, C. (no date). “Academic honesty and Online Courses”, Department of Economics, Weber State University, Ogden, UT.

5. Healy, P. (2001). "Online Testing, with no cheating”, Boston Globe, page C1, January 29.

6. Rowe, N. (2004). "Cheating in Online Student Assessment: Beyond Plagiarism”, Online Journal of Distance Learning Administration, Volume VII, Number 11, State University of West Georgia, Distance Education Center.

7. Varvel, V. (2005). "Honesty in Online Education”, Pointers and Checkers, Volume 6 (1). 